JCMC 3 (3) December 1997

\title{
Message Board
}

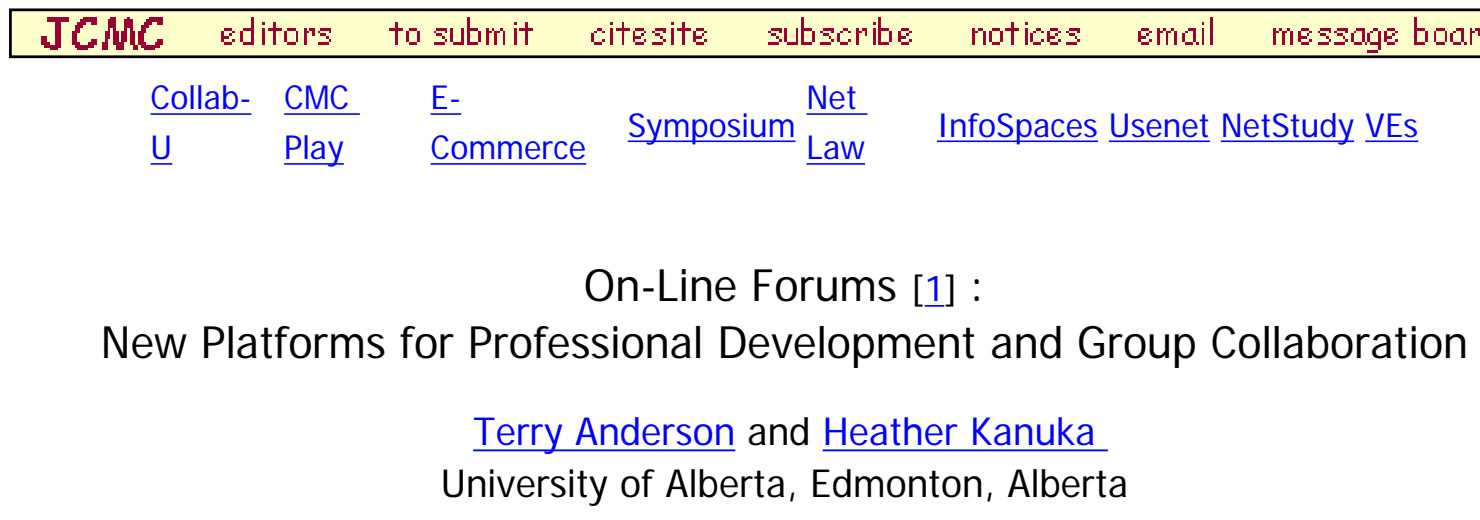

\section{Table of Contents}

- Abstract

- Introduction

- Literature Review

- Professional Development

- Moderator's Role

- Diffusion of Innovations

- Methodology

- Results

- Discussion

- Conclusions

- Footnotes

- References

- About the Authors

\section{Abstract}

This study evaluated the output, level of participation and perceptions of effectiveness and value among participants in a virtual forum. Twenty-three experts in the field of adult education and community development were invited to participate in a three-week interactive session using a WWW-based, asynchronous computer conferencing system. Data gathered through surveys, interviews, transcript analysis and on-line discussion revealed that this technology has relative advantage for organizers and sponsors, but is perceived by most users as being less satisfying than face-to-face interaction. The on-line forum was found to be observable, trialable and relatively easy to use (compared with existing tools), indicating that this innovation has potential to become a widespread medium for continuing professional education.

\section{Introduction}


Research on professional education indicates that the capacity to support collaboration, reflection, and professional development, as well as to overcome barriers of time and place, makes the use of on-line forums a potentially useful and cost effective innovation [(Anderson, 1996)]. However, in spite of this research, face-to-face learning environments are still generally assumed to be better than on-line forums to support such collaborative learning processes [(Harasim, et al., 1995)]. Harasim, et al. claim there is no evidence to support this assumption. Hiltz [(1988a, 1994)] argues that they may even be superior to the traditional face-to-face environment. The debate continues to rage on.

Fundamentally, however, it really does not matter what the research indicates as the best method for learning when determining whether or not on-lines forums will be used in continuing professional education. What matters is whether or not the participants perceive the forum as a valued process. If they do, they will be more likely to adopt it [(Rogers, 1995)] as a platform for continuing professional development. Specifically, if innovations, such as online forums, have certain perceived attributes the probability of adoption will be greater [(Rogers, 1995)]. The perceived attributes include the perception by potential adopters that the innovation has relative advantage, is not overly complex, is compatible with existing values and customs, can be tried on a limited basis, and has observable results. Given this rationale, the purpose of this study was to assess the potential for adoption of on-line forums for continuing professional education as it relates to the perceived value to the participants with an authentic on-line forum trial.

Although the main focus of this study was the evaluation of perceived value among participants in a three-week Virtual Forum, it also evaluated participation levels and related access issues. Twenty-three experts in the field of adult education and community development were invited to participate in a three-week interactive session. The Forum had four objectives. (1) The creation and validation of a policy paper that dealt with the critical issue of providing equitable access to learning technologies. This issue is of crucial importance if we are to decrease the widening gap between the information privileged and those deprived of the technology and the opportunities provided through the technologies. (2) The development of communication, collaboration and technical skills, and expertise by the participants through the use of on-line technologies. (3) The assessment of the electronic forum technology as an effective vehicle for the Office of Learning Technologies to achieve its corporate objectives and to increase its service capacity, at affordable cost to a larger, bilingual group of Canadians. (4) Testing of the amount of translation and support needed to maintain effective communications between users of both Canada's official languages when undertaking collaborative tasks using on-line media.

The Canadian Office of Learning Technologies (OLT) funded the Forum and the evaluation. All participants were asked to take part in the research component of the forum, and all agreed. The technology used to host the Forum was Caucus ${ }^{\circledR}$. Caucus ${ }^{\circledR}$ is a non-threaded, World Wide Web-based, asynchronous computer conferencing system. Conferencing systems such as Caucus ${ }^{\circledR}$ make group collaboration possible, independent of time or place. Specifically, according to [Harasim, et al. (1995)] "Computer conferencing is based on the concept that software facilities can be built into the computer to allow groups to coordinate and organize the material in a manner appropriate to their communication objectives" (p. 19). The Caucus ${ }^{\circledR}$ software organizes discussion topics by items. There were a total of 18 items in the on-line forums, as follows:

\begin{tabular}{|c|c|c|}
\hline $\begin{array}{c}\text { Item } \\
\#\end{array}$ & Item Title & $\begin{array}{c}\# \text { of } \\
\text { postings }\end{array}$ \\
\hline
\end{tabular}




\begin{tabular}{|c|c|c|}
\hline 1 & Introduce yourself & 31 \\
\hline 2 & Help & 41 \\
\hline 3 & Participants List & 1 \\
\hline 4 & Social Access to learning Technologies: Background Paper & 1 \\
\hline 5 & L'accès social aux technologies d'apprentissage : Document de trav & 1 \\
\hline 6 & $\begin{array}{l}\text { Informed Consent to Participate in the OLT/BTA sponsored } \\
\text { conference }\end{array}$ & 1 \\
\hline 7 & $\begin{array}{l}\text { Consentement éclairé pour participer au Forum sur l'accès social } \\
\text { aux technologies d'apprentissage parrainé par le Bureau des } \\
\text { technologies d'apprentissage. }\end{array}$ & 2 \\
\hline 8 & $\begin{array}{l}\text { Conference Purpose and Agenda / L'objectif et le programme de la } \\
\text { conférence }\end{array}$ & 2 \\
\hline 9 & Definition of Social Accesss & 10 \\
\hline 10 & Findings / Conclusions & 32 \\
\hline 11 & Case Studies / Études de cas & 13 \\
\hline 12 & Common Elements / Éléments communs & 1 \\
\hline 13 & Bibliography / Bibliographie & 1 \\
\hline 14 & Factors / Facteurs & 9 \\
\hline 15 & Ensuring Social Access / Comment peut-on faire & 17 \\
\hline 16 & Principles / Principes & 1 \\
\hline 17 & Libraries / Bibliothèques & 2 \\
\hline \multirow[t]{3}{*}{18} & Thank You and Farewell / Merci et au revoir & 3 \\
\hline & Reflections/Pensees & 6 \\
\hline & Total postings: & 144 \\
\hline
\end{tabular}

The entire conference discussion is on-line and available for public viewing at http://johns. largnet.uwo.ca/ caucus/olt-bta/english.html.

Technical staff and a contracted moderator supported the participants. The technical support for the forum was provided by the Network for Ontario Distance Education (NODE). The NODE's activities included: (1) forum construction including conference creations, creation of user names and passwords, the creation of graphics, and graphical links and templates; (2) encouraging participation with welcoming messages and personal phone calls to participants who had not joined the conference after the start date; (3) technical support through a user 
guide, introduction messages, and a help icon; (4) support for the moderator with setup issues and regular updates as to which participants had joined the forum as well as who had not and why.

The value of the forum for participants was evaluated using the criteria developed by Rogers [(1995)]. Data was gathered relating to participants' perception of value through participant surveys, telephone interviews, and transcript analysis and on-line discussion.

Problems addressed in this research included (1) evaluation of perceived value of an online forum used for collaborative continuing professional development and (2) the effect that these attributes have on the rate of adoption.

\section{Literature Review}

\section{Professional Development}

Evaluating on-line forums as a vehicle to support professional development depends upon a definition and purpose of continuing professional education. According to [Sch•n (1987)] and [Cervero (1988)], facilitators of professional development activities have a responsibility not only to provide information but also to assist professionals in developing a critical and analytical way of considering knowledge, to provide opportunities for professionals to practice using their judgment skills, and to assist professionals in developing new knowledge based on practice. To achieve these goals, professionals seek to identify and solve work-related problems through the use of new and better systems of action. The purpose of professional development activities, then, is to provide an opportunity for professionals to improve the way they increase their unique body of knowledge through a critical and analytical process of acquiring, practicing and adopting new knowledge. How best to achieve this purpose, according to [Cervero (1988)], is through the rich resources of practical knowledge acquired by other professionals. When professionals search for similarities from across the profession, it can "yield a fresh exchange of ideas, practices, and solutions to common problems" [(Cervero, 1988 , p. 15)]. The best way to facilitate this kind of learning is through small discussion groups, staff meetings, conferences and workshops using such instructional methods as brainstorming, analogies, case studies, simulations, role playing and reflection [(Cervero, 1988; Nowlen, 1988; Sch॰n, 1987)].

However, there are professional development activities that are, at the very least, non-cost effective and may also be inappropriate and perhaps even discriminatory. For example, faceto-face discussion groups would be ineffective and inappropriate for the professional who is hearing impaired. Physical disabilities are just one example of barriers to participating in professional development activities. Other examples include lack of access, financial constraints [(Anderson, 1966)] and the two most frequently expressed barriers to participating in adult education: time and place [(Cross, 1981)]. A possible solution to overcoming these major barriers is the increased use of distributed and asynchronous learning technologies such as on-line forums.

On-line forums are an example of a method that could satisfy these needs in a cost-effective manner. Specifically, on-line forums provide (1) freedom from time constraints (participants can participate when and if they choose); (2) time for reflection (participants decide when and if they choose to participate); (3) opportunities to research and back up assertions; and (4) support for cost effective global communication [(Anderson, 1996)]. Well-developed virtual conferences can "create a stimulating and supportive learning environment without forcing 
participants to congregate at a particular location or time" [(Anderson, 1996, p. 2)]. Finally, learning activities that introduce participants to potentially useful learning and communications technologies provide a valuable training and exposure function.

\section{Moderator's role}

Essential to creating a stimulating and supportive on-line learning environment is the moderator. [Hiltz \& Turoff (1978)] first identified the role of the moderator. Over the past two decades the role of the moderator has, according to Tagg [(1994, p. 40)] "been variously defined as one that motivates, provides support and stimulates..., guides or "weaves" the topic in order to keep it on the right track..., provides strong leadership..., coaches students on communication skills ..., facilitates discussion..., and secures continuity in a medium in which a sense of overview may be lost..., while simultaneously attempting to "humanize the technology" and act as a trouble-shooter...."

According to [Mason (1997)] the role of the moderator of any on-line conferencing activity typically involves special responsibilities and authorities, in both the technical and facilitating sense: "at a technical level, the moderator can delete or alter any message in the conference and is responsible for removing irrelevant or offensive material. At an educational level, the moderator guides the discussion, stimulates participation and often offers intellectual leadership. The role of on-line ... [moderators], therefore, combines elements of teacher, ... [chairperson], host, facilitator and community organizer." In addition, according to [Harasim, et al. (1995)], "when moderators are actively involved--responding regularly, posting new material, encouraging activities and discussions--students respond with enthusiasm and regular participation" [(Harasim, et al., 1995, p. 43)].

[Berge (1992)] also concurs with the above assumptions, noting that the moderator takes on various roles including facilitator, manager, filter, expert, editor, promoter, marketer, helper and fireman. According to [Klem \& Snell (1996)], the functions of the moderator must also promote collaborative learning. Collaborative learning is "the idea that small interdependent groups of [participants] work together as a team to help each other learn ... [participants] must understand, critically evaluate, and apply instructional materials. One of the best ways for ... [participants] to develop these skills is to perform tasks that can only be accomplished by these higher-level learning processes. These processes are leveraged if a group works collaboratively to help each other." Supporting this view, [Comstock \& Fox (1995)] state that "no individual can know enough to solve the tough problems we are facing as workers and managers, in science or society. As learners our knowledge is expanded through interactions with a diversity of other learners. The learning community becomes a vehicle for bringing this diversity of learners into a dialogue." Given the conditions of a well-developed on-line forum, effectively moderated by a skilled moderator facilitating collaborative learning, the question is: Will practicing professionals adopt this learning technology?

\section{Diffusion of innovations}

Will participants in continuing professional education activities adopt and use on-line forums? If so, why? If not, why not? Diffusion, as defined by Rogers, is the process by which an innovation is communicated through certain channels over time among the members of a social system. Rogers' diffusion theory comprises four theories from a variety of disciplines that result in the creation of a meta-theory of diffusion [(Surry \& Farquhar, 1997)]. Rogers' four theories include: 
1. the innovation decision process theory that states that diffusion is a process that occurs over time and can be seen as having five distinct stages (knowledge, persuasion, decision, implementation and confirmation);

2. the individual innovativeness theory that maintains individuals who are predisposed to being innovative (innovators) will adopt an innovation earlier than those who are less predisposed (laggards);

3. the rate of adoption theory claims that innovations are diffused over time in a pattern that typically begins with slow growth before experiencing a period of relatively dramatic and rapid growth (resembling an s-shaped curve); and

4. the theory of perceived attributes which states that an innovation will undergo an increased rate of diffusion if the prospective adopters perceive the innovation has relative advantage, is not overly complex, is compatible with existing values and customs, can be tried on a limited basis and has observable results.

While all four of the theorized relationships described above will influence the rate of adoption, it is the last (the theory of perceived attributes) that this research used as a framework. Specifically, the researchers' interests were (1) evaluation of perceived value of an online forum used for collaborative continuing professional development and (2) the effect that these attributes have on the rate of adoption. The theory of perceived attributes argues that if an individual perceives a new innovation as having relative advantage, is not overly complex, and is compatible with existing values and customs it has a greater probability of being adopted. Questions relating to the adoption of on-line forums that the researchers were interested in investigating included: Are on-line forums better than face to face forums? Is getting to know and communicating with the forum participants easier on-line or more difficult than face-to-face? Is the use of emerging technologies, such as on-line forums, important to the participants personally? Are on-line forums perceived as a valued platform for continuing professional education? Is the opportunity to try an on-line forum beneficial? Are cost and time issues perceived as important benefits when using on-line forums? In light of the issues that the researchers were interested in investigating, it was determined that Rogers' fourth theory (the theory of perceived attributes) was an appropriate framework for the study.

\section{Methodology}

The study employed a variety of research instruments and techniques, thereby creating a "mixed method" [(Caracelli \& Green, 1993)] study. The methods used by the researchers included a survey instrument, telephone interviews, machine logs (postings) and informal transcript analysis. All the active participants were asked to complete the survey; 15 of the 18 participants did so. It was not clear why three of the participants did not complete the survey-although all participants were very busy individuals and the time required to complete the survey may have been prohibitive. Thirteen of the participants completed the survey located on the World Wide Web, one participant completed the survey via fax, and another completed the survey using an e-mail attachment. Nine of the eighteen participants were contacted for telephone interviews. The researchers did not randomly select the nine participants; rather, an attempt by the researchers was made to gather information from participants using a stratified sample procedure. The stratified sample included the following three categories based upon participation: (1) actively participating on the on-line forum (7-15 postings); (2) moderate participation (3-6 postings); and (3) low participation(0-2 postings). Eight of the nine participants agreed to a telephone interview and the ninth participant sent an extensive email. The data from each method was used to triangulate and authenticate the observations and analysis of the on-line forum. Following is an expanded description of each of the methods used in this study. 
Survey Instrument: The survey was developed using [Rogers' (1995)] theory of perceived attributes as a theoretical base; it also included additional demographic and usage questions. The survey consisted of 43 items (Likert Scale, 1-5 where 1 is strongly agree and 5 is strongly disagree), 7 demographic data questions and three open ended questions [(See the survey at: http://www.atl.ualberta.ca/survey/olt english.html)]. The theory used to frame the questionnaire was the theory of perceived attributes (adoption, compatibility, complexity, observability and trialability). As mentioned, the researchers felt that this framework would be useful in providing a base upon which to compare the attributes of a technology's effectiveness and its potential for adoption by specific groups for specific tasks. Through examining these stages of adoption, deficiencies in the innovation that preclude some users from adopting it might also be brought to light.

Telephone Interviews: The survey was followed with a telephone interview to nine participants. The interviews were designed to ask questions and probe issues extracted from the survey and from analysis of the forum transcripts. The interviews were semi-structured in that a set of questions was established prior to the interviews. The questions were as follows:

1. From where did you access the forum? (i.e., Work? Home? Traveling?)

2. Did you have any technical problems accessing the forum? Please describe.

3. Please comment on the length of the forum. Too short? Too long?

4. What was your understanding of the tasks or expected outcome of the forum?

5. Did the forum achieve these goals?

6. Did the forum provide adequate opportunity and incentive for you to contribute your ideas on issues related to social access to learning technologies? Why or why not?

7. Did the forum increase your knowledge about issues related to social access?

8. There was not much discussion in French. Do you think it is necessary to have separate, unilingual conferences or was the bilingual conference effective?

9. What things could be changed to improve future forums?

Interviewees were given the opportunity to comment upon any additional features or concerns related to the forum or its administration.

Transcript Analysis: The written record of discourse of the forum provides a rich source of data for evaluators. No formal analysis of the content was undertaken, but reading the transcript helped the researchers identify and draw out the potential value of the forum process, which was confirmed or refuted through the survey and interviews. A second evaluation on a subsequent forum undertook a more systematic transcript analysis [(Anderson \& Kanuka, 1997)]

\section{Results}

The last part of the on-line survey was used to obtain descriptive demographic data on those individuals who participated in the on-line forum. These data helped determine the generalizability of the survey data. The data indicated that the majority of the participants who responded to the survey were between the ages of 41-45. Thirty-six (36) percent of the survey respondents were female while 64 percent were male. Twenty-one (21) percent of the survey respondents described their computer experience level as expert, 36 percent described it as good, 36 percent as fair, 7 percent as novice and none of the survey respondents indicated having no computer experience. These levels of computer experience are probably above North American averages but are probably typical of working professionals. Other data collected included information on the amount of time participants spent participating in the forum per day, with whom the participants discussed the proceedings, and whether or not 
they would recommend further on-line forums. The majority of the survey respondents stated that they spent between 16-30 minutes (31\%) or 31-60 (31\%) minutes per day participating on the on-line forum. All survey respondents stated that they had discussed the on-line forum with family, colleagues and/or friends.

Survey Instrument Analysis: The most interesting results of the on-line survey are reported in Table 1 . Part $A$ of the online survey was used to identify the extent to which the participants, in comparison to face-to-face interaction, perceived relative advantages of participating in an on-line forum. Sixty-five (65) percent of survey respondents did not agree that the online forum was as good as what would have been exchanged in a face-to-face forum (36\% disagreed; $29 \%$ strongly disagreed). In addition, $79 \%$ of survey respondents stated they were more limited in their ability to communicate (discuss, ask questions) with other participants than in a face-to-face forum (29\% strongly agreed; $50 \%$ agreed). Finally, $82 \%$ of respondents felt that it was more difficult to socialize with other participants than in a face-to-face forum (38\% strongly agreed; $54 \%$ agreed) but also felt emerging learning technologies (such as the on-line forum) were important to them personally ( $43 \%$ strongly agreed; 36\% agreed).

Table 1: Online survey results

Question ( 1 = strongly agree; $5=$ strongly disagree)

$(n=15)$

\begin{tabular}{|l|c|c|}
\hline Part A & M & SD \\
\hline $\begin{array}{l}\text { The information exchanged during the on-line forum was better than what } \\
\text { would have occurred in a face-to-face forum. }\end{array}$ & 3.79 & 1.05 \\
\hline $\begin{array}{l}\text { Getting to know and talking with other participants was easier with on-line } \\
\text { forums than with face-to-face forums. }\end{array}$ & 4.21 & 0.58 \\
\hline $\begin{array}{l}\text { I was more limited in my ability to communicate (discuss, ask questions) with } \\
\text { other participants than I would have been in a face-to-face forum. }\end{array}$ & 2.07 & 1.31 \\
\hline & & \\
\hline Part B & & \\
\hline $\begin{array}{l}\text { Using emerging learning technologies, such as this on-line forum, is important to } \\
\text { me personally. }\end{array}$ & 1.93 & 0.80 \\
\hline The technical skills needed to participate in this forum are skills I use in my job. & 1.79 & 0.83 \\
\hline $\begin{array}{l}\text { On-line forums are becoming a valued platform by my colleagues for continuing } \\
\text { professional education. }\end{array}$ & 2.71 & 1.14 \\
\hline The overall feeling of my colleagues is that on-line forums are of little value. & 3.64 & 1.05 \\
\hline & & \\
\hline Part C & & \\
\hline I liked the way the on-line forum was structured. & 2.71 & 1.07 \\
\hline The daily schedule of activities for the on-line forum was too structured. & 3.64 & 0.74 \\
\hline I had no trouble navigating in the on-line forum. & 3.21 & 1.01 \\
\hline I had no technical problems getting on-line to the forum. & 2.79 & 1.48 \\
\hline & & \\
\hline
\end{tabular}




\begin{tabular}{|l|c|c|}
\hline The opportunity to try this on-line forum was beneficial. & 1.64 & 0.84 \\
\hline This on-line forum was a waste of my time. & 4.14 & 0.68 \\
\hline $\begin{array}{l}\text { As a result of participating in the on-line forum, I no longer have any } \\
\text { uncertainties about the technical skills required to participate in this type of } \\
\text { activity. }\end{array}$ & 2.50 & 1.08 \\
\hline
\end{tabular}

Part B of the on-line survey was used to identify the participants' views with regard to the compatibility of the forum in ways that were technically, socially and professionally congruent with their working conditions and preferences. Respondents stated that the technical skills needed to participate in this forum were skills they used on their jobs (29\% strongly agreed; $57 \%$ agreed). Finally, there was low consensus in responses with the perceived value of this kind of platform as a professional development activity (14\% strongly agreed; $29 \%$ agreed; $36 \%$ were neutral; $14 \%$ disagreed; $7 \%$ strongly disagreed).

Part C of the on-line survey was used to identify the participants' perception of the complexity of the forum with respect to: (1) the technical skills required to participate; (2) the structure of the forum; (3) ease of navigation and dialogue contribution; and (4) access to the central conferencing system or a local computer system. The results showed a split in responses about how the participants felt with respect to the difficulty of navigating on the online forum (29\% agreed; 36\% disagreed; 29\% were neutral; $7 \%$ strongly disagreed); there was also a split in responses relating to technical difficulties getting on-line (29\% strongly agreed; $21 \%$ agreed; $43 \%$ disagreed; $7 \%$ strongly disagreed).

Part D of the survey asked the participants about the perceived value of the on-line Forum. All participants agreed that the opportunity to try the Forum was beneficial (54\% strongly agreed; $46 \%$ agreed), and only $7 \%$ agreed that the time was wasted. Also interesting was the number of respondents that reported increased confidence in their technical skills as a result of participation in the forum (7\% strongly agreed; $33 \%$ agreed; $25 \%$ were neutral; $25 \%$ disagreed).

Telephone Interviews and Qualitative Responses to the Survey: Semi-structured telephone interviews were conducted with 8 participants; a ninth responded to the request for an interview with a lengthy e-mail reply. The researchers found it difficult to contact interviewees, which underscored the comment from many that these participants were very busy people. The interviews followed a semi-structured format with 9 questions asked of each respondent.

The major themes arising from the interviews were:

- Although some participants accessed the forum from home, the majority connected from work.

- The interviewees reported relatively few problems getting access to or navigating within the Caucus(tm) system.

- The respondents' view of the appropriateness of the length of the forum ( 3 weeks in total) brought a mixed response. Half of the respondents thought the time was about right, while the others were split between thinking it was too long and too short. Those who posted and participated heavily seemed to think the duration of the conference should not be increased--they were giving significant time (one listed 2-4 hours daily)-and seemed reluctant to continue any longer. Those who logged on and posted less frequently seemed to find the conference too short, typically noting "any shorter and I wouldn't have had time." The organization of the Forum (one-week introduction and two weeks of discussion) seemed to result in an effective compromise between those who suggested either a shorter or a longer time frame. 
- Nearly all interviewees cited the goal of providing a forum for discussion among colleagues as an important reason for their participation. When asked if this goal had been met, all but one replied that they had benefited from the exchange. Typically, one interviewee (a very active poster) commented "this was as good as any other (face-toface) conference."

- All but one of the interviewees who participated stated that the forum increased their knowledge about issues related to social access, thus verifying the forum's achievement of one of its major goals, which was to increase the content related knowledge of the participants.

Our sense from the interviews was that those who participated more expressed higher levels of satisfaction and attributed greater value to the on-line experience.

\section{Discussion}

The study revealed several deficiencies in the Forum esperience that might discourage potential users from adoption. With regard to the relative advantage of on-line forums, most participants felt that it was more difficult to socialize with other participants than in a face-toface forum. Based on this data, questions that need to be asked include: Can this be overcome through more creative moderating techniques that foster greater collaborative learning activities or building learning communities? Will this be overcome, as participants of on-line forums become more experienced with the medium? Are on-line forums creating a new kind of social form where participants will need to develop new social skills to cope with socializing electronically? If this is so, are comparisons with face-to-face forums really relevant or even applicable? Will newer technologies that support higher levels of social presence [(Short, et al.1976)] than text based conferencing help overcome these impediments to communication? Do these new forms of interacting lead to new ways of experiencing and developing learning which are not the same as face-to-face communities but are capable of supporting meaningful learning and satisfying social interactions? Or, are these issues that are simply a characteristic of the medium that cannot be overcome?

As noted in the results section, most participants felt that the information exchanged during the on-line forum was not as good as information that would have been exchanged in a faceto-face forum and felt more limited in their ability to communicate (discuss, ask questions) with other participants than in a face-to-face forum. Based on this data, it needs to be determined if effective moderation can facilitate the movement of on-line communication from reactive to fully interactive. Specifically, is there an art to the moderator's role whereby facilitation skills can move on-line communication from the transmission of information to what [Rafaeli \& Sudweeks (1997)] refer to as a social reality? According to Rafaeli \& Sudweeks, "face-to-face conversation cannot be used as the standard of comparison for group $\mathrm{CMC}$ [and] fully interactive communication requires that later messages in any sequence take into account not just messages that preceded them, but also the manner in which previous messages were reactive. In this manner interactivity forms a social reality".

Based on the data from the on-line survey, the Forum appears to hold little or no relative advantage compared to face-to-face forums with regard to socialization and ability to communicate. However, the participants are not the only ones to whom relative advantage of the innovation must be assessed. Employers, for example, of the participants would likely experience relative advantage as their employees would have minimal work time loss and no travel time loss. Another example of a group that might experience relative advantage of online forums would be the sponsors of the forum who also have no travel or accommodation expenses. Indications from the sponsor (OLT) confirm high satisfaction with the resulting 
product.

Would the session have been more productive if carried on through face-to-face interaction? Assuming (based on the survey data) an average of 45 minutes logged on per participant over the 15 working days of the Forum, the extent of the participation could be estimated as about 12 hours total time devoted to the forum. This is considerably less than the combined travel and session time that would be required for a two-day face-to-face gathering in a central location. It must be kept in mind that participants were spread across Canada, a geographic distance that necessitates two days travel time for most participants to attend any face-toface meetings. Thus, there may be relative advantage in terms of time committed by the participants. The moderator of the session and the investigators were also impressed with the extent of expert opinion provided by the participants. They observed participants building upon the knowledge of others, indicating additional relative advantage over individual consultation. A final area of relative advantage was the value of having participants bring not only their thoughts but those of colleagues, spouses and others with whom the participants interacted during the three weeks of the Forum.

The results of the survey indicated that most participants felt the on-line forum was compatible (part B of the survey, Table 1) with their working conditions and preferences, the structure was straightforward and made it easy to post comments (not too complex, part C of the survey, Table 1) and the opportunity to experiment resulted in less uncertainty (trialability, part D of the survey, Table 1). The participants did not perceive relative advantage of the forum (part A of the survey, Table 1). However, there may have been perceived relative advantage for the moderator, sponsors and employers of the forum. If in fact those who organize, support, and require forum participation perceive relative advantage, widespread adoption of on-line forums will likely occur in the near future. However, significant numbers of participants may continue to find the experience less than satisfactory--at least when compared to face-to-face forums.

\section{Conclusions}

The various data sources used in this study (survey, interviews, active participation, transcript analysis and discussions with the organizers) lead the researchers to the following conclusions.

First, the forum's goals of enhancing the participants knowledge of both the process of on-line consultation and understanding of issues (related to increasing social access to learning technologies) were achieved. One hundred percent of the participants who responded to the survey indicated that the forum was beneficial; 93\% recommend that the OLT continue to sponsor this type of activity.

Second, the framing of the research question around [Rogers' (1995)] adoption of innovation research indicates that on-line forums have a very good chance of being adopted as an effective and functional means of consultation and collaborative work with professionals. Based on the results of the research, this type of consultative and group activity is perceived by the participants and the forum's organizers as adding value to policy development, enhancing networking opportunities, and contributing to continuing education for professionals.

\section{Footnotes}

[1] For the Latin scholars we confess we had difficulty with the use of the Latin plural term for forum (fora). 


\section{References}

- Adam, S. (1996). Technological convergence in higher education: Are educators ready? [Online]. Available: http://elmo.scu.edu.au/sponsored/ausweb/ausweb96/educn/adam/ paper.html

- Anderson, T. (1996). The virtual conference: Extending professional education in cyberspace. International Journal of Educational Telecommunications, 2(2/3), 121-135.

- Anderson, T., \& Kanuka, H. (1997). Evaluating the workplace center on-line forum: Knowledge construction and learning communities. Unpublished Research Report. Office of Learning Technologies, Human Resources, Canada.

- Berge, Z (1992). The role of the moderator in a scholarly discussion group (SDG). [Online]. Available: http://star.ucc.nau.edu/ mauri/moderate/zlbmod.html

- Caracelli, V. J., \& Greene, J. (1993). Data analysis strategies for mixed-method evaluation designs. Educational, Evaluation and Policy Analysis, 15(2), 195-207.

- Cervero, R. (1988). Effective continuing education for professionals. San Francisco: J ossey-Bass Publishers.

- Comstock, D., \& Fox, S. (1996). Computer conferencing in a learning community. [Online]. Available: http://www.seattleantioch.edu/VirtualAntioch/compcon1.5.htm

- Cross, B. P. (1981). Adults as learners: Increasing participation and facilitating learning. San Francisco: J ossey-Bass Publishers.

- Harasim, L., Hiltz, S. R., Teles, L., \& Turoff, L. (1995). Learning networks. Cambridge, MA: The MIT Press.

- Hiltz, S. R., \& Turoff, M. (1978). The network nation: Human communications via computers. Reading, MA: Addison-Wesley.

- Hiltz, S. R. (1988a). A virtual classroom on E.I.E.S., Vol. 1: Learning in a Virtual Classroom research report 25. Newark, NJ: Center for Computerized Conferencing and Communication.

- Hiltz, S. R. (1994). The virtual classroom: Learning without limits via computer networks. Human-Computer Interaction Services. Norwood, NJ : Ablex Publishing Corp.

- Klemm, W., \& Snell, J . (1996). Enriching computer-mediated group learning by coupling constructivism with collaborative learning. EJIST 1(2)[Online]. Available: http://www. usq.edu.au/electpub/e-jist/abstrac2.htm

- Mason, R. (1997). Moderating educational computer conferencing. [Online]. Available: http://star.ucc.nau.edu/ mauri/papers/mason.html 
- Nowlen, P. (1988). A new approach to continuing education for businesses and the professions: The performance model. New York: Macmillan Publishing Company.

- Rafaeli, S. \& Sudweeks, F. (1997). Networked interactivity. Journal of Computer Mediated Communication, 2(4) [Online]. Available: http://207.201.161.120/jcmc/vol2/ issue4/rafaeli.sudweeks.html

- Rogers, E. M. (1993). Diffusion of Innovations (3rd Edition). New York: The Free Press.

- Rogers, E. M. (1995). Diffusion of Innovations. (4th Edition). New York: The Free Press.

- Schøn, D. (1983). The reflexive practitioner: How professionals think in action. New York: Basic Books, Inc., Publishers.

- Schøn, D. (1987). Educating the reflective practitioner. San Francisco: J ossey-Bass Publishers.

- Short, J., Williams, E., \& Christie, B. (1976). The social psychology of telecommunications. London: Wiley.

- Surry, D. W., \& Farquhar, J. D. (1997). Diffusion theory and instructional technology. Journal of Instructional Science and Technology, 2(1). [Online]. Available: http://www. usq.edu.au/electpub/e-jist/vol2nol/surry/surry.htm

- Tagg, A. C. (1994). Leadership from within: Student moderation of computer conferences. The American J ournal of Distance Education. 8(3), 40-50.

\section{About the Authors}

Terry Anderson is an Associate Professor and Director of Academic Technologies for Learning in the Faculty of Extension, University of Alberta. Terry has been a presenter at numerous conferences and has been widely published in the area of technologies for learning and distance education . Heather Kanuka is a Research Coordinator at the University of Alberta and a Ph.D. student at the University of Alberta.

Addresses: Terry Anderson, Faculty of Extension, University of Alberta, 8303-112 Street, Edmonton, Alberta, T6G 2T4 CANADA. Heather Kanuka, Department of Educational Policy Studies, 7-133K Education Building South, University of Alberta, Edmonton, Alberta, CANADA. 